\title{
"CRIMINICULTURA": POLICÍA Y DELITO EN VALPARAÍSO DURANTE LAS PRIMERAS DÉCADAS DEL SIGLO XX
}

\author{
"Criminicultura": police and crime in Valparaiso \\ (Chile) during the first decades of the XX century
}

\author{
Vania Cárdenaz Muñoz*
}

\begin{abstract}
RESUMEN
Las presiones ejercidas sobre las justicias y policías frente al avance delictual es parte de las continuidades históricas en toda sociedad $^{1}$. El peligro puede transmutarse de acuerdo a lo que cada sociedad considere atentatorio de determinados bienes, de esta forma se construye un trazo del sujeto peligroso de acuerdo al discurso predominante. En el Chile liberal, las funciones preventivas y represivas de las policías representaron el refugio último de la seguridad para las clases dominantes, la "sociedad ilustrada, el público que solo pide a la policía que cumpla con sus deberes afianzándoles de esta manera sus vidas y sus propiedades". Este trabajo hará referencia a la influencia de corrientes de pensamiento, discursos de "sentido común" vertidos por la prensa y la propia visión que poseía la policía sobre la delincuencia y el delincuente en Valparaíso durante las primeras décadas del siglo XX. Se postula la preeminencia de posturas sustentadas en la práctica, que no obstante articulan parte de las ideas criminológicas predominantes en la época y la influencia que ejercen los discursos de la elite sobre la prensa frente al avance del sujeto peligroso. Para ello, se trabajará con archivos policiales de la Intendencia de Valparaíso, la Revista de Policía de Valparaíso, prensa del periodo, entre otros.
\end{abstract}

Palabras-clave: Delincuencia; policía; criminología.

cardvania@gmail.com

* Doctorado en Historia, Universidad de La Plata. E-mail para contato: 2015 . 


\begin{abstract}
Society's pressures over both Judiciary and Law Enforcement Agencies regarding issues of increasing crime rates are part of historical continuities1. Claims and perceptions of danger can chance according to what any society considers as threats to certain values and behaviors. The profile of "dangerous" people is then shaped by a given dominant discourse. In liberal Chile, preventive and repressive functions performed by police officers represented the last shelter or sanctuary for the dominant classes who considered themselves as "learned society, demanding police protection and action to defend its life and properties." This article studies the influence of schools of thoughts, "common sense" discourses in the press, as well as the police own views, regarding crime and criminals in Valparaíso, Chile, during the first decades of the XX Century. The piece argues that most of these perspectives were based on practices and routines. However, these same views took into account criminological ideas of that period as well as elite opinions through the press to deal with "dangerous individuals". The sources to study this topic are police documents from Valparaíso Police Department, Valparaíso's Police Magazine, and the early XX century press.
\end{abstract}

Keywords: Crime; Police; Criminology.

\title{
Introduccion
}

De acuerdo a las fuentes censales disponibles para inicios del siglo XX en $\mathrm{Chile}^{2}$, la provincia de Valparaíso concentraba un importante crecimiento urbano que venía desarrollándose desde fines del siglo pasado. En 1907 esta densidad se expresaba en la ciudad de Valparaíso, concentrando el $58 \%$ de la población residente en todos los departamentos de la Provincia ${ }^{3}$.

El principal puerto de la república, era considerado la segunda ciudad del país en población y riqueza. Una importante fuente de ingresos se concentraba en la actividad comercial del

2 La información existente corresponde al censo de 1907.

3 La población total de los departamentos de Valparaíso, Quillota, Limache y Casablanca era de 281.385 habs., mientras que la ciudad de Valparaíso - capital provincial y departamental- contaba con 162.447 habs. 
"emporio de la República" con sus depósitos de productos y mercaderías ingresadas desde el exterior. Este escenario de desarrollo e intercambio mercantil, forma parte de las características propias de un puerto, caracterizado por la permanente movilidad de poblaciones que llevan a cabo movimientos migratorios internos y externos: comerciantes nacionales y extranjeros que llegaban a instalar sus negocios, población rural que arribaba desde los departamentos vecinos atraída por el desarrollo de las obras y la industria o grupos de hombres y mujeres que llegaban atraídos por el desarrollo mercantil y terminaban desempeñando labores al día (gañanes) o practicando la mendicidad en las calles, aumentando los cinturones de pobreza ante la mirada horrorizada de la elite ${ }^{4}$.

En este contexto, los primeros años del siglo XX en Valparaíso se presentan como un espacio privilegiado para observar el accionar policial frente a las tensiones de un ordenamiento que desde el siglo anterior había fortalecido su marco legal para resguardar la propiedad privada en el país. El incremento de la densidad poblacional y la insuficiencia de los cuerpos policiales para cubrir territorios vastos e irregulares, se convertía en el escenario propicio para que cundiera la voz de alarma por el aumento de la criminalidad. En este periodo se visualiza la transformación del proyecto policial, que anteriormente había centrado su quehacer en el cumplimiento de funciones asociadas a la baja policía -salubridad, aseo y ornato de las calles- hacia aquellas tendientes a la mantención del ordenamiento liberal, llegando a ocupar un lugar central en su producción la vigilancia, control y represión de aquellos sectores que representaban algún peligro para la mantención de este ${ }^{5}$.

Esto se conjugaba con la existencia de miradas desconfiadas y prejuiciosas sobre las conductas de los pobres, que desde el siglo XIX había permeado a vastos sectores de la elite, expresados mediante discursos de políticos e intelectuales de la época que explicaban las conductas de los pobres -la enfermedad, el vicio, la mendicidad, entre otras- desde un doble prisma, regenerativo y

4 Romero, Luis Alberto, Qué Hacer con los Pobres, Elites y sectores populares en Santiago de Chile 1895, Buenos Aires, Ed. Sudamericana, 1997.

5 Cárdenas Muñoz Vania. El orden gañán: historia social de la policía de Valparaíso, Concepción, Editorial Escaparate, 2013, 307 p 
represor. Este conjunto de discursos y prácticas que estuvieron a la base del ordenamiento republicano, representaban las visiones del sector dominante sobre la figura de los pobres, antecediendo el desarrollo de las ideas positivistas sobre el estudio de la conducta criminal. La diferencia con la irrupción del nuevo paradigma, que en Chile se acogió hacia fines del siglo XIX y especialmente en las primeras décadas del siglo siguiente, es que estos prejuicios alcanzaron un soporte científico que corroboraban las pasadas impresiones ${ }^{6}$, los que fueron aprehendidos en los discursos y prácticas de médicos, jueces y policías e incorporados tanto en los discursos legos, como en la prensa e incluso en medios oficiales de la época. Una caricatura de 1910, exhibía una imagen de un delincuente, que al estilo Frankenstein había sido reconstruido en base a los principales rasgos de políticos de Valparaíso, bajo esta el texto: "según las teorías de Lombroso y de Ferri, éste sería el tipo de delincuente que debía ser "eliminado"7.

\section{El peso de los numeros}

"La historia de la delincuencia se encuentra en los prontuarios", exponía el director de un semanario policía, haciendo referencia a la escasez de recursos con que había iniciado su funcionamiento el gabinete de identificación de la policía de Santiago a fines del siglo XIX y su posterior estado de abandono ${ }^{8}$. Lo cierto es que más allá de las limitaciones existentes, hubo un importante despliegue de energías para calcular, catalogar y archivar datos sobre el delito durante los primeros años del siglo XX, considerando la escasez de personal y las distracciones que esta labor burocrática

6 León León, Marco Antonio. Construyendo un sujeto criminal. Criminología, criminalidad y sociedad en Chile, siglos XIX y XX. Santiago de Chile, Centro de Investigaciones Barros Arana, 2015.

7 Revista Sucesos, IX, 422, 6 octubre 1910.

8 Valladares, Aurelio, Instrucción Policial Amena, Santiago de Chile, Imprenta Antigua Inglesa, 1915, pp. 94-101. 
representaba para los servicios de prevención y represión del crimen. Esta impronta estadística se advierte en el incremento de los datos existentes en los archivos: se presentaba la delincuencia por edades, nivel de instrucción, sexo, estado civil e instrucción de los detenidos; elaborando comparaciones por años que servían de base para la elaboración de consolidados bajo categorías tales como "estadística de ebriedad", "criminalidad infantil" o "delitos", lo que en ocasiones servía de base para establecer comparaciones con la estadística europea.

Hacia finales del siglo XIX, estos ejercicios entregaban sus resultados: según el recuento que realizaba la sección de seguridad, la mayor parte de los delitos aprendidos y puestos a disposición del juez correspondía a hurtos ( $80 \%$ del total), seguido de lesiones y asalto, mostrando un pequeño porcentaje de personas detenidas por homicidio. Al igual que en el resto del país, en Valparaíso hacia el 1900 , la detención por hurtos "es de todas las edades y parece ser de todas las condiciones y estados". Los delitos asociados a la propiedad privada cobraban relevancia en el marco de las investigaciones practicadas por los pesquisas, seguidas por un discreto porcentaje de delitos contra las personas ${ }^{9}$. En cambio, el trabajo de la sección de orden -de carácter preventivo- daba cuenta del incremento de otro tipo de infracciones en las cuales las detenciones por desorden y ebriedad ocupaban gran parte del trabajo de los guardianes. El incremento de la ebriedad era una fuente de preocupación constante de las policías, quienes realizaban un particular análisis a propósito del incremento de las detenciones de ebrios practicadas entre los años 1901 y $1912^{10}$, señalando que: "la ley en nada vino a extirpar este vicio, sino que, por el contrario, siguió su curso en forma alarmante, pues los reos aprehendidos aumentaron" ${ }^{11}$.

En cuanto a los oficios de los detenidos, la estadística policial- concordante con la información censal- se concentra en labores habituales del puerto, concentrándose mayormente en hombres (cuadro $\mathrm{N}^{\circ} 1$ ) cuyo mayor porcentaje estaba representado

9 Revista de Policía de Valparaíso, año 7, núm. 90, julio de 1913.

10 La Ley de Alcoholes que estableció la penalidad sobre la embriaguez, fue promulgada 18 de enero del 1902 y entro en vigencia el 18 de abril del mismo año.

11 Revista de la Policía de Valparaíso, año 7, núm. 90, Julio de 1913, pp. 59. 
por el oficio de gañán, seguidos por empleados particulares, jornaleros, gente de mar y sin oficio, todos ellos responsables de cometer delitos de ebriedad y desorden. Las mujeres en tanto, eran detenidas mayoritariamente por ejercer la prostitución y hurtos, y los principales oficios eran de prostitutas, lavanderas, cocineras y costureras. Las edades de hombres y mujeres detenidos se concentraban en el tramo de 16 a 30 años, especialmente entre los 21 a 25 , el estado civil predominante era el de soltero (con un mínimo porcentaje de viudas), la mayor parte de ellos alfabetizados ${ }^{12}$.

Cuadro No 1: Número de personas aprehendidas por la policía 1908-1912

\begin{tabular}{|c|c|c|c|c|c|c|}
\hline Sexo & $\mathbf{1 9 0 8}$ & $\mathbf{1 9 0 9}$ & $\mathbf{1 9 1 0}$ & $\mathbf{1 9 1 1}$ & $\mathbf{1 9 1 2}$ & Total \\
\hline Hombres & 25.529 & 21.503 & 17.217 & 19.084 & 18.649 & $\mathbf{1 0 1 . 7 8 2}$ \\
\hline Mujeres & 2.579 & 1.968 & 1.887 & 2.011 & 1.566 & $\mathbf{1 0 . 0 1 1}$ \\
\hline
\end{tabular}

Fuente: Revista de la Policía de Valparaíso.

La estadística criminal del periodo estuvo sujeta a importantes críticas sobre su falta de rigurosidad y representatividad; en el afán policial por clasificar y calcular, se incluía a reos, condenados y detenidos indiscriminadamente incorporando estos datos como base para la confección de los resúmenes. Junto a estos sesgos, mirada desde el presente, esta información genera serias interrogantes que sugieren tomar distancia sobre los análisis posteriores, los que no incorporaban aspectos que actualmente se toman en consideración dado el avance de la criminología; tales como el peso que tienen los delitos que en determinada época son objeto de mayor o menor carga punitiva o la mayor vulnerabilidad de ciertos grupos frente a la acción judicial o policial ${ }^{13}$. Un ejemplo de lo anterior lo reflejaba la reflexión realizada por funcionario anteriormente mencionado, frente al aumento de las detenciones por ebriedad. Este incremento -que en 1903 correspondía al 60\% de las detenciones anuales de Valparaíso- obedecía a promulgación de una ley que otorgaba mayor acción coercitiva a policías y jueces frente a estas prácticas, de forma que el ebrio que antes de 1902 cada mañana

12 Consolidado de la estadística policial de los años 1908, 1911 y 1916.

1992.

13 Larrauri, Elena. La herencia de la criminología crítica, México, Ed. Siglo XXI, 
se confundía con el personal del cuartel realizando el aseo como un tipo de sanción, posteriormente pasó a ser detenido ${ }^{14}$.

Así también, estudios recientes han demostrado que durante fines del siglo XIX e inicios del XX, el delito contra la propiedad en las principales ciudades de Chile se extendió a todas las clases sociales. Sin embargo, los delitos practicados por bandidos de levita y corbata no causaron el sensacionalismo alcanzado por el robo efectuado por el "ladrón conocido", permaneciendo ausente de los registros policiales y mayormente silenciado por la prensa, no obstante el gran daño que estas rapacerías -en forma de estafas, falsificaciones y apropiación dolosa de propiedades fiscalesrealizaron a los intereses individuales y fiscales ${ }^{15}$. En base a la investigación realizada de Daniel Palma, estas evidentes omisiones se relacionaban con la mayor vulnerabilidad -a nivel de influencias, económicas y personales- del delincuente reflejado en la estadística, a diferencia del delincuente de cuello y corbata, quien contó con medios que le permitieron evadir la acción policial y judicial; pasando a ocupar el lugar de las ausencias en las fichas policiacas y la prensa del periodo.

Con todo, estas cifras nos entregan luces sobre el énfasis represivo de determinados tipos de delitos, así como de los sujetos a los que se consideró "peligrosos", construyendo con estos elementos una trama de recursividades plasmadas en la estadística. En este sentido, un papel importante estuvo representado por la difusión de ideas predominantes sobre el delito y el delincuente, desde fines del siglo XIX, conformado desde el discurso positivista y denominado como la "criminología del otro", para identificar al delincuente desde una matriz que naturalizaban la diferencia con el alienado, personaje que se caracterizaba por tener poco en común con el nosotros ${ }^{16}$.

En Chile, desde los aportes de la antropología positivista y su influencia -especialmente desde el campo de la medicina- se concedió la categoría de "discurso científico" a los prejuicios que no eran nuevos en la sociedad, tales como los postulados que asociaban

14 El Mercurio de Valparaíso, jueves 2 de abril de 1903.

15 Palma Alvarado, Daniel. Ladrones. Historia social y cultural del robo en Chile, 1870 1920, Santiago, Lom Ediciones, 2011.

16 Sozzo, Máximo. Inseguridad, prevención y policía, Quito, Flacso, 2008, p. 6. 
criminalidad-raza y el argumento sobre la existencia de una predisposición hereditaria. No obstante el modelo positivista se basó en la aplicación de métodos y procedimientos que se sustentaban en la estadística para dotar de objetividad a estas ideas ${ }^{17}$. Estas miradas estereotipadas sobre el sujeto peligroso fueron replicadas desde distintos sectores desde fines del siglo XIX, quienes alarmados frente a la emergencia de la llamada "cuestión social", las migraciones campo-ciudad y su potencial de criminalidad entre la multitud desconocida que circulaba en las ciudades, demandaba un mayor control por parte de los servicios de orden para controlar estas verdaderas plagas que generaban la alama de las clases acomodadas.

En este contexto, a fines del siglo XIX, las policías chilenas habían incorporado tecnologías de identificación mediante el uso rudimentario de las técnicas de bertillonage y antropometría, que posteriormente se depuraron mediante experiencias de intercambio con las policías argentinas y otras a través de instancias de instrucción y correspondencia ${ }^{18}$. Estas tecnologías aplicadas para el control de la reincidencia se combinaban con medidas de control y vigilancia preventiva. Durante los primeros años del siglo XX, en Valparaíso se practicaba el empadronamiento poblacional, lo que suponía que el guardián debería poseer un conocimiento detallado de los movimientos de los habitantes bajo su vigilancia, se estableció un sistema de fichaje entre los vagabundos que se desplazaban en sectores de industria y comercio, para extenderse a otros grupos sociales considerados como sospechosos: vendedores ambulantes, conductores, suplementeros, gente de mar entre otros debían fotografiarse e inscribirse en los registros laborales y obtener permisos para traficar en aquellos sectores en los cuales laboraban.

El positivismo y las ideas lombrosianas, tuvieron una amplia recepción desde fines del siglo XIX, y los esfuerzos formativos en estas materias se dirigieron a la investigación o al conocimiento práctico, en este caso se orientaban a funcionarios de prisiones y policías. El influjo del positivismo criminológico favoreció el

17 León, León, Ob.Cit., p. 45.

18 Palacios Laval, Cristian. "Entre Bertillón y Vucetich: las tecnologías de identificación policial. Santiago de Chile, 1893-1924". En: Revista Historia y Justicia $\mathrm{N}^{\circ} 1$, Santiago de Chile, 2013, 1-28. ISSN 0719-4153, revista.historiayjuticia.org. 
intercambio de conocimientos, a través de publicaciones o participación de los principales difusores en encuentros de divulgación; este movimiento fue especialmente fructífero en las primeras décadas del siglo XX, facilitando la circulación de estas doctrinas entre grupos de trabajo de distintos países. En este caso, la figura de José Ingenieros concentró parte importante de estos intercambios, la amplia obra del ítalo-argentino incluía sus publicaciones (Criminología, 1907), ensayos y trabajos publicados en Archivos de Psiquiatría y Criminología (1902-1913) de la que fue su fundador, junto con los trabajos efectuados en su papel de director de instancias de observación e investigación, dependientes de la policía y Penitenciaría Nacional. Su extenso trabajo en este campo -sin desconocer sus aportes a otros ámbitos del conocimiento- contribuyó fuertemente al fortalecimiento de redes de trabajo y comunicación en y desde otros continentes.

La influencia de estos postulados en los circuitos policiales de Valparaíso, incluyeron la difusión de trabajos clásicos de Bertillón, Vucetic, Lombroso y especialmente los trabajos del Dr. Luis Gámbara, Delegado General de la Escuela Positivista Penal en las Repúblicas Hispano-Americanas ${ }^{19}$. En sus conferencias realizadas en Santiago y Valparaíso -esta última en julio de 1905- Gámbara exponía sus ideas sobre delincuencia infantil, la influencia del ambiente social en la creación del delincuente y la prevención social, así como el rol preventivo de las instituciones de beneficencia ${ }^{20}$. También dictó un curso de Derecho Penal a la Sociedad Médica de Santiago, cuyo contenido -publicado en 1906- exponía ampliamente sus planteamientos sobre prevención social. Desde una mirada higienista, proponía el estudio de cada una de las causas del delito: la miseria, el alcoholismo, el juego, el ocio y la indigencia representan factores de la criminalidad que serían susceptibles de modificar a través de la educación y la beneficencia. La centralidad del componente moralizador expuesto por este autor se haría presente en

19 Autor del libro "La policía científica" (1920) y colaborador de la Revista Policial de la provincia de Buenos Aires (1931).

$20 \mathrm{Zig}$ Zag, I, n 23, 23 de julio de 1905. Publicación posterior sobre el tema: Conferencia dada en el Ateneo de Santiago por el Dr. Luis Gámbara, delegado General de la Escuela Positiva Penal. Santiago de Chile, Imprenta del Comercio, 1906. 
el discurso policial, especialmente si con ello se lograba también evitar la propagación de la "tempestad socialista y anarquista" que golpeaba al viejo continente; el autor era partidario del reforzamiento de la labor policial para controlar la libertad de emigración, verdadera "válvula de escape a la criminalidad" ${ }^{21}$. Gámbara alcanzó una importante presencia en la publicación porteña, que desde el año 1921, divulgaba in extenso sus "Estudios sobre policía", en los cuales describía las causas del retraso policial en la prevención del crimen, dada su falta de preparación técnica y la prevalencia de prácticas que descansan sobre el empirismo de sus agentes. En este periodo mantenía la crítica frente a su eficacia policial en la prevención del crimen, no obstante estas ideas eran matizadas con un mayor peso dado a la policía en la prevención del delito, en relación al periodo anterior en que estas acciones eran delegadas en la prevención social.

A diferencia de la difusión de los trabajos de Gámbara, las publicaciones policiales de Valparaíso omiten figuras importantes en el ámbito de la criminología, como es el caso de Ingenieros o Enrico Ferri, especialmente este último conocido difusor de las ideas lombriosianas, quien visitó Valparaíso en octubre de 1910 para dictar una conferencia sobre el tema. Ambos intelectuales eran portadores de las ideas socialistas que en la época abarcaban un amplio margen ideológico. La visita de Ferri fue profusamente difundida por la prensa porteña ${ }^{22}$, se presentaba como un orador polémico, que habría "levantado roncha" entre algunos círculos que se habían sentido ofendidos con sus atrevidas declaraciones ${ }^{23}$. En la oportunidad, recibió los ataques de la prensa conservadora que lo presentaba como "agitador", generando réplicas inmediatas como las difundidas en el mismo mes, bajo el título de "Charla contra Ferri" que ofrecía un periodista italiano -el Conde Serralunga Langhi- en el recinto de la Universidad Católica de Santiago ${ }^{24}$.

21 Curso de Derecho Penal Positivo en 10 lecciones dado en la Sociedad Médica de Santiago por el Dr. Luis Gámbara. Delegado General de la Escuela Positivista Penal en las Repúblicas Hispano-Americanas, Santiago de Chile, Imp. de los Hnos. Ponce, 1906.

22 Una caricatura muestra a un elegante Ferri, acompañada del texto: "Enrico, que predica contra los ricos y siempre se queda En rico" Sucesos, Valparaíso, IX, 422, 6 octubre 1910.

23 Sucesos IX, núm. 423, 13 octubre 1910.

24 Sucesos IX, núm. 424, 20 octubre 1910. 
En las fuentes policiales consultadas, la difusión de estas ideas se articulaban desde un terreno eminentemente práctico, mediante un quehacer transmitido desde la medicina legal, con visiones deterministas que asociaban enfermedad-pobreza y vicio. Las influencias del positivismo y la criminología positiva se expresaban en el discurso policial con distintos énfasis, desde la incorporación de conceptos vagos e imprecisos sobre los postulados lombrosianos, hasta la transferencia de sus principales exponentes. Se publicaban extractos de textos de Lombroso sobre perfiles criminales o notas extranjeras que exponían los postulados de Garofalo y otros. Esto era matizado con enérgicas críticas efectuadas por corresponsales locales frente al "manoseo científico [que] está sacando un código de reglas que nos distrae de lo principal", refutando los postulados clásicos, a partir de las destrezas adquiridas por el funcionario de la calle. El origen de la criminalidad se fundaba según este análisis en el medio ambiente y la "atmósfera corruptora" que influiría sobre el desarrollo de los instintos criminales. Con ello, la teoría lombrosiana resultaba por completo inaplicable en Chile, por no considerar la enseñanza moral y la educación, elementos que influirían más que todas las anormalidades físicas en el desarrollo de la conducta delincuencial. En estas críticas se dejaba entrever la primacía del componente regenerativo sobre el determinismo lombrosiano.

Lombroso es un sabio del que nos hemos permitido sospechar que le debe mucho a la moda (la criminalidad también la tiene), pero de su sabiduría nos hemos permitido siempre extraer un apéndice: el de las conformaciones indefectiblemente criminales ${ }^{25}$.

No obstante, las explicaciones deterministas continuaban representando un marco explicativo frente a los llamados problemas de trascendencia social. Hasta las primeras décadas del siglo XX,

25 Santibáñez, Antonio, "La niñez abandonada y la vagancia”, Revista de Policía de Valparaíso, año IV, $\mathrm{N}^{\circ}$ 51, 31 de diciembre de 1910. 
estas miradas fusionaban racismo y determinismo social; la "degeneración de las razas" que afectaba a Europa debilitando a las nuevas generaciones, se hacían presente en Valparaíso a través de la decadencia de las costumbres: el alcoholismo, el juego y la vagancia eran el camino directo a la decadencia de la raza nacional y el paso a la criminalidad en los sectores populares, aunque estas costumbres -se decía- ya estaban en camino de expandirse a otras clase sociales ${ }^{26}$.

\section{Las siluetas del peligro}

A inicios del siglo XX, el escritor Víctor Domingo Silva radicado hacía un año en Valparaíso- a través de las páginas de Pluma y Lápiz llamaba la atención sobre los delitos de sangre ocurridos en Valparaíso, "espectáculos reales" de tal magnitud que se sobreponían a las mejores representaciones europeas, crispando los cabellos de los lectores de noticias policiacas. Para el autor identificar el origen de estos crímenes no era tarea difícil: "en los barrios bajos de Valparaíso -o altos, puesto que están en los cerros -hai insignes maestros en el arte de las cuchilladas curvilíneas i de los destripamientos instantáneos ${ }^{27, \%}$. En este periodo de expansión de la crónica roja, otras revistas de circulación regional como Sucesos y El Mercurio de Valparaiso se sumaban a las voces de advertencia por el avance del delito y la necesidad de fortalecer la vigilancia policial. Estos llamados, aun cuando no representaban novedad alguna en las páginas de la prensa, llegaban a convertirse en caja de resonancia de discursos emanados desde las clases propietarias sobre el temor al avance de la combinación pobreza-criminalidad.

En efecto, la pobreza se ubicaba en las partes altas del puerto y el discurso dominante identificaba el foco del crimen en estos lugares, espacios a los cuales no llegaban los avances de la

26 Revista de Policía de Valparaíso, año II, N 14, 30 de noviembre de 1907.

27 John Pencil (seudónimo de Víctor Domingo Silva) "Cosas del puerto", Pluma y Lápiz, n75, 4 de mayo de 1902. 
modernidad implementados en el plan, dificultando la acción policial, ya sea por la irregularidad de los terrenos, falta de alumbrado público o porque los escasos funcionarios concentraban la vigilancia en áreas de mayor movimiento comercial. La prensa de la época deslizaba permanentes llamados a la autoridad para fortalecer el servicio policial en los cerros que rodeaban la cuidad, los que habían incrementado su población y requerían mayor vigilancia para continuar su adelanto, pues "nadie se atreverá a sobrevivir en la altiplanicie si no está seguro de que su vida y sus intereses están suficientemente resguardados"28. La mirada policial operaba desde una matriz explicativa que coincidía con los postulados de la escuela positivista, según los cuales su estudio debería considerar el territorio donde habitaba el individuo, por representar este uno de los factores de influencia social que determinaba el desarrollo criminal. Con ello, la acción de la policía se concentraba en los lugares altos mayormente poblados, como el popular cerro Cordillera -habitado por marineros y trabajadores portuarios - en donde "sería hacer prodigios de vigilancia evitar las raterías y latrocinios en una población tan extensa, compuesta en algunos barrios de gente de dudosas costumbres y antecedentes" ${ }^{29}$. El año 1902, el $60 \%$ de los reos ingresados a la Sección eran habitantes de los cerros, especialmente del famoso, inmenso y poblado cerro Barón

...tradicional recinto de las fechorías, con los centenares de cuartos que son verdaderas sentinas donde se aloja la escoria de la prostitución y los abundantes laberintos llamados conventillos, donde escapan a la mirada de la policía los rateros y los encubridores, los ladrones y los asesinos, son los depósitos que arrojan el inmenso contingente de reos que ofrece la Sección y que retratan con exacto colorido la fisonomía moral de sus habitantes ${ }^{30}$.

28 “La reorganización de las policías”. El Mercurio de Valparaíso, 17 de junio de 1900. 29 Nota de Prefectura de Valparaíso, 15 diciembre 1904. Intendencia de Valparaíso, vol.1107.

30 El Mercurio de Valparaíso, jueves 2 de abril de 1903. 
Este reportaje, publicado en 1903, incluía un extenso capítulo con estadísticas policiales, ornamentadas con las reflexiones del corresponsal, para quien después de haber observado la "idiosincrasia de las colectividades", resultaba lógico comprender la superioridad numérica de los delincuentes en los sectores populares de la ciudad. De esta misma forma, se construían un marco explicativo que incorporaba a toda una categoría de seres peligrosos y ajenos que despertaban la mirada desconfiada de la elite, incluyendo a vagos, mendigos, borrachos, trabajadores desocupados y mujeres de poca decencia. Sobre ellos primó la "mirada preventiva" de la policía, atenta a las advertencias de la clase propietaria.

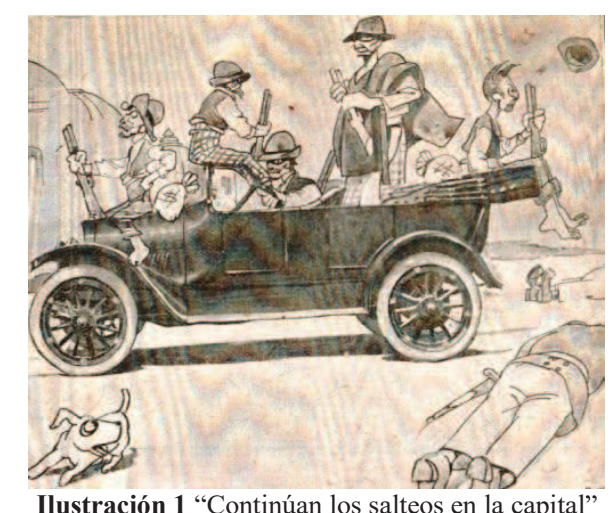

Revista Sucesos, Año XVIII, N 903, 15 de enero de 1920

Como se indicó anteriormente, los perpetradores de delitos eran en su mayoría hombres, con una presencia comparativamente menor de mujeres, entra las cuales la mayor cantidad de detenciones se producía entre prostitutas y ladronas de tiendas o "tenderas". Los archivos policiales concentran cantidad importante de acciones referidas a ataques violentos, extorsión y explotación de todo tipo en las cuales las mujeres figuraban en el rol de víctimas, cuyos perpetradores eran mayoritariamente hombres, entre los cuales se encontraban los propios policiales. Lo interesante en este punto, es la imagen que se construye sobre la mujer criminal y el acopio de información sobre el tema, que no se condice con la información que 
entregan las fuentes, incluyendo la estadística. El delito femenino ocupaba las páginas de las publicaciones oficiales, incorporando exponentes extranjeros y criollos que disertaban sobre la naturaleza criminal de la mujer. El año 1911, el aclamado César Lombroso era publicado por el semanario policial, en el artículo confirmaba sus conclusiones sobre la naturaleza histérica -"inevitable en el criminal nato, sobre todo en la mujer"- y la similitud entre la mujer libertina y la criminal, en cuanto a sus características innatas: la falsedad y la debilidad, disfrazada esta última en una gran astucia para desarrollar sus engaños ${ }^{31}$. Por su parte, los repórters criollos trataban de explicar la baja presencia estadística de las mujeres, asignándoles un rol accesorio en el mundo delictual, desde una mirada en común con la lógica lombrosiana: su naturaleza impostora. Las mujeres eran consideradas un auxiliar del delincuente hombre, pasando desapercibida para la acción policial. La llamada "mujer centinela" dispondría de recursos asociados a su condición femenina:

mucho más perfectos que los de los hombres en el arte del engaño...tiene la ventaja que despierta menos sospecha, excita la compasión... dispone del inmenso arsenal de la coquetería femenina para excitar en el hombre la pasiones sensuales ${ }^{32}$.

Hasta la segunda década del siglo XX, la delincuencia infantil representaba un tema de actualidad en las principales ciudades del país. Una carta dirigida a José Ingenieros por un abogado de Concepción, sugería la preocupación por el tema, consultándole por su artículo "Los niños vendedores de diarios y la delincuencia precoz", citado en Criminología, que no había encontrado en Chile ${ }^{33}$. Estos temas concentraban la agenda policial en los centros urbanos,

31 Revista de Policía de Valparaíso, núm. 54, 1 de marzo de 1911.

32 Nemo. "La Mujer auxiliar del ladrón”. Policiaca, Año 1, Núm. 1, Santiago de Chile, enero 1918

33 Carta manuscrita de A. Spottke a J. Ingenieros, Concepción, 27 de febrero de 1920. Fondo José Ingenieros, Biblioteca CEDINCI, Buenos Aires. 
estrechando la vigilancia sobre los niños vagos. Se planteaba que estos preferían dormir en el rincón de una puerta, antes de "doblegarse a la autoridad paterna", frente a la burla de la figura paternal, las prácticas correctivas sobre estos "señores de su albedrío" eran aplicadas a manos del representante de la máxima autoridad que los detenía, "acarreándolos" a las comisarías o escuelas.

Un peligro inmediato lo representaban los muchachos que deambulaban por el malecón, socializando con los trabajadores que se encontraban en los sitios de descarga de mercaderías. Este escenario era observado con recelo por la policía, por considerar que estos encuentros se convertían en verdaderas "escuelas del crimen", pues a través de la charla con los trabajadores los pequeños se educaban en las fórmulas delictivas entregadas por los adultos. La fusión entre presuntos y potenciales delincuentes requería del acoso policial, a partir de una mirada en la que confluían componentes de regeneración y determinismo social, puesto que "todo niño abandonado se convertirá en criminal", era necesario apartar al pequeño delincuente haciendo alusión a su calidad de vago- de esa "atmosfera corruptora". Nuevamente, entraban en escena las categorías lombrosianas, esta vez para graficar su inaplicabilidad en chicos que a simple vista "engañaban" a cualquiera que buscase algún signo que delatara su vida criminal, pues "en ningún caso se veían mandíbulas poderosas, ni pómulos sobresalientes", de forma que Lombroso "los habría indultado a simple vista" dada su fisiología, de una dulzura incomparable $e^{34}$.

De esta forma, se conformaban los trazos del potencial peligro, que incluía a un grupo variopinto que obstaculizaba el paso de la elite a la anhelada modernidad, no obstante se mantendría como "plaga de miserables" hasta a lo menos la segunda década del siglo $\mathrm{XX}$ :

la ciudad está cubierta de una plaga de mendigos, asquerosos y harapientos, niños, mujeres y ancianos, Valparaíso, año IV, $\mathrm{N}^{\circ}$ 51, 31 de diciembre de 1910. 
seres todos, sin excepción aptos para el trabajo, que detienen a medio mundo en las calles más centrales en demanda de una limosna ${ }^{35}$.

Lo anterior se agudizaba con los movimientos migratorios que habían representado desde el siglo anterior un desequilibrio para el ordenamiento liberal. Inicialmente lo fueron las migraciones campo-ciudad, con un flujo y reflujo de los trabajadores de los campos a los pueblos, que según la prensa no hacía "más que aumentar la desmoralización y los crímenes". El itinerario de los pobres estaba predefinido: terminado el tiempo de cosechas, regresaban a las ciudades buscando otra ocupación y al no encontrarla ingresaban instintivamente al circuito del delito ${ }^{36}$. En el contexto de la crisis salitrera que afectaba al norte del país, el año 1914 desembarcaban en Valparaíso grupos de trabajadores desocupados, la prensa exponía el pavor que suscitaban los "varios miles de individuos sin trabajo, [quienes] no pueden menos que constituir una amenaza para el orden público". Según la publicación, el desarrollo industrial iba a contrapelo de estos movimientos migratorios que desafiaban el frágil ordenamiento liberal. Con la llegada de los hombres el peligro se expandía desde distintas esferas, una de ellas era el aumento de negocios de licores, juego y prostíbulos; por otra parte, la figura del obrero desocupado representaba un peligro por su propia condición, pues "tarde o temprano se convertiría en amenaza" según la deducción ocio y "pillaje", a esto se agregaba la llegada de individuos peligrosos que se filtraban entre los trabajadores: "maleantes que no desaprovecharían un minuto para cometer desórdenes" $"$ "

Con esto último se hacía referencia a los agitadores, socialistas o anarquistas "incorporados, como lepra funesta en la masa trabajadora de nuestra población". La policía responsabilizaba de este estado de cosas a los gobiernos y sus políticas de colonización, cuyo único resultado habría sido atraer a esta hez social: hombres que por

35 El Diario Ilustrado, núm. 435, Santiago 23 de noviembre de 1921, p.3.

36 El Mercurio de Valparaíso, 03 de enero 1865.

37 "El aumento de la policía" El Mercurio de Valparaíso, enero 1914. 
su falta de competencia laboral y sus ideas revolucionarias habían sido expulsados de Europa y llegaban al país que los recibía "bajo el

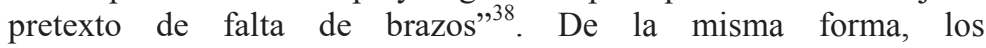
desplazamientos desde países vecinos, como Argentina -tras la promulgación de la Ley de Residencia- atraía a elementos políticos que se confundían con peligrosos rufianes que llegaban a establecer el negocio de trata de blancas, luego de haber sido expulsados de su país $^{39}$. La cruzada contra este peligro exhortaba a los agentes a vigilar escrupulosamente el funcionamiento de las sociedades obreras en que "tan funestas ideas se arrojan sobre el trabajador ignorante ${ }^{40 "}$.

Desde la mirada policial, el obrero era visto como una presa fácil no solo de los "charlatanes utopistas", sino también de toda clase de corrupciones que degeneraban sus energías y deprimían su capacidad de trabajo. El lupanar, el garito y la taberna, representaban el foco de la desmoralización, pues engendraban delincuentes entre los hombres del bajo pueblo, de forma que hasta el dócil peón bajo su influencia se transformaría fácilmente en ladrón, tahúr o vago. Estos espacios, que tampoco habían sido considerados bajo el análisis lombrosiano, serían la bandera de batalla de la policía frente al avance de la criminalidad.

Mientras los obreros sobrios y mejor orientados de la vida tratan de guiar o conducir a sus compañeros al terreno de la dignidad, yo, me dije, me colocaré en condiciones de poder atacar los antros de perdición de estos desheredados: el lupanar, el garito, la taberna. ¿Cómo?, incorporándome al cuerpo que tiene esta misión: la Policía ${ }^{41}$.

38 Luis A Santibáñez, "La misión de las sociedades obreras", Revista de Policía de Valparaíso, año $\mathrm{V}, \mathrm{N}^{\circ} 56,1$ de abril de 1911.

39 Oficio 134, del Jefe de la Sección de Seguridad al Prefecto de Policía de Valparaíso, Octubre de 1913.

40 Antonio Santibáñez, "La represión del anarquismo", Revista de Policía de Valparaíso, año III, $\mathrm{N}^{\circ}$ 39, 31 de diciembre de 1909.

41 Devia, Enrique, “¿Por qué soy paco?”, Revista de Policía de Valparaíso, año 1 Número $1,1^{\circ}$ de marzo de 1921 . 


\section{Emilio Dubois o la policia burlada}

Este título forma parte de un cuadro de una obra de teatro escrita el año 1907, sobre un importante suceso que remeció la escena criminológica a inicios del siglo XX en Valparaíso. Su personaje principal, Emilio Dubois, fue señalado como uno de los primeros asesinos en serie y hasta los actuales tiempos forma parte importante de la cultura popular porteña. Las publicaciones de prensa y literarias hablaban de "la mano maestra de un bandido de alta escuela", exponiendo una aguda crítica a la falta de rigurosidad policial para investigar el crimen, así como el uso de apremios ilegítimos por parte de los funcionarios para extraer la confesión de tres sospechosos, quienes al final la investigación habían resultado ser inocentes. La repetición de crímenes y la impunidad de los mismos generaron alarma en la sociedad y el comercio, sintetizada en el informe remitido por el Juzgado del Crimen a la Corte de Apelaciones el 15 de diciembre de 1905, en el cual se informaba que los habitantes habían concurrido en masa solicitando permisos para cargar armas prohibidas $^{42}$. En este escenario, mediante un Decreto Supremo se disolvió la policía de seguridad, por no contar con los elementos que garantizaran la seguridad de la ciudadanía.

La lectura del proceso que derivó en la sentencia de muerte para Dubois, deja en claro a lo menos dos situaciones: se trataba de un delincuente profesional, con facilidad para desplazarse y mimetizarse en distintos espacios, además se apartaba del perfil criminal, no coincidiendo su imagen con la del sujeto peligroso que reposaba en el ideario de la época.

En efecto, la presencia de Emilio Dubois -o Luis Amadeo Brihier según un acta de nacimiento encontrada- pasó desapercibida ante los ojos de policías y victimas. Su figura representaba a un hombre moderado, de vestir cuidadoso, con signos de refinamiento como el uso de sombrero y gemelos- que dominaba varios idiomas, desplazándose con soltura entre las clases acomodadas. Declaraciones

42 "La sentencia a muerte de Emilio Dubois", Boletín de la Policía de Santiago. Año VIII, Santiago de Chile, núm. 55-58, marzo de 1907. 
de testigos lo definieron como un "hombre decente", la prensa opinaba que no era un ser vulgar y hasta un guardián que cruzó palabras con el bandido cuando huía de la escena del crimen de Tillmans, declaró que por un momento pensó que se trataba de "un malhechor disfrazado de caballero". La actitud de Dubois hacia el guardián, era una muestra de la intimidación que suscitaba entre el personal subalterno el trato con las clases acomodadas: "no temas guardián, soy el dueño" fue suficiente argumento para alejar al funcionario del lugar.

Otro elemento distintivo fue la facilidad con que este hombre se desplazaba: en el trascurso de una década desde su llegada de Europa, residió al menos en 18 ciudades de 7 países latinoamericanos, desempeñando todo tipo de oficios. Durante su presencia en Bolivia, había sido acusado del asesinato de un hombre en Oruro, burlando la acción de las policías bolivianas que solo se enteraron de su presencia en Chile cuando el juez chileno les solicitó los antecedentes. Este itinerario, le dotó de una serie de habilidades y una personalidad que ostentaba seguridad: uno de los testigos informaba que al comentar la impunidad de estos crímenes, Dubois le había respondido que estos eran cometidos "a la alta escuela, como en Europa [por lo cual] serían muy difíciles de pesquisar por la justicia de Chile".

En su estadía en Chile, no habría desempeñado oficio alguno, viviendo habitualmente de la mendicidad en versión refinada: tenía cartas en diferentes idiomas para sus llamados "suscriptores". Estos eran mayoritariamente comerciantes que entregaban sus aportes para auxiliar a alguna familia extranjera, firmando una lista que Dubois utilizaba como introductoria para llegar a otras personas y de esta forma acumulaba información que posteriormente era corroborada mediante la observación de los movimientos de sus futuras víctimas. Durante este tiempo elude la acción policial, siendo detenido en una sola ocasión, durante 14 días a raíz de escándalos.

Este perfil no encajaba con el sujeto peligroso que suscitaba la desconfianza policial. Por lo mismo, su detención acaparó la atención de policías, jueces y de la sociedad porteña en general. Las caricaturas hacían mofa del cambio de apariencia en los hombres (bigote, sombrero, vestimenta) que no deseaban tener parecido alguno con un criminal con el que habían socializado, sin llegar a percibir diferencia alguna entre este y el "nosotros". En este periodo, hasta el 
célebre Dr. Gámbara viajó a Valparaíso para entrevistarse con el "primer asesino en serie" del que se tenía conocimiento y estudiar su vida. Por otra parte, la serie de descuidos y omisiones de la policía de Valparaíso y Santiago -incluyendo pericias solicitadas al tristemente célebre Eugenio Castro, por ese entonces jefe de seguridad en la capital- daban cuenta de una marcha rezagada en materia de investigación criminal, que continuaba funcionando en base a una visión arcaica y prejuiciosa sobre el delincuente y la delincuencia. El mismo semanario policial lo reconocía a propósito de los casos Dubois y Beckert, indicando que sus "métodos son muy anticuados, impropios para ponerlos al frente del arte moderno de Matar"43.

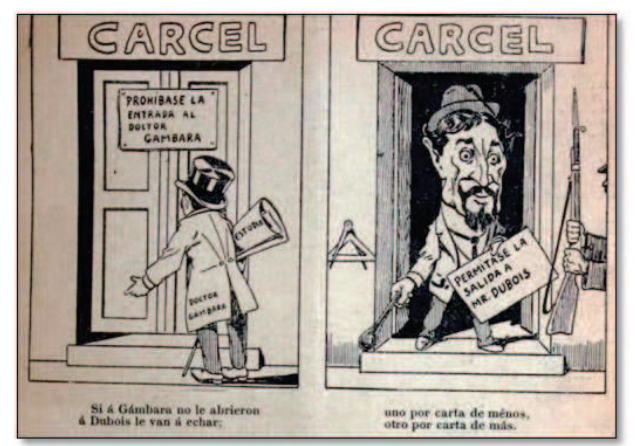

Ilustración 2 Revista Zin Zal, año 1, nº 6, 7 marzo 1907.

\section{Conclusion}

Durante las primeras décadas del siglo XX, Valparaíso representaban un escenario propicio para el desarrollo de culturas desconocidas para el accionar policial, dado el importante desarrollo de la industria, el comercio y el atractivo que esto generaba para la industria del delito. En este periodo de transición del quehacer 
policial, cada vez más centrado en los delitos contra la propiedad, al interior de las policías continuaba primando un saber práctico que miraba con recelo el desarrollo de modernas teorías sobre la criminalidad y el sujeto criminal; se decía que el policía de calle era el mejor conocedor de las culturas de bajo fondo, la observación, el diálogo que se producía naturalmente entre delincuentes y funcionarios dotaban a estos últimos de un conocimiento especializado, un olfato policial que se sobreponía a las explicaciones teorizantes sobre la conducta criminal, cuestión que llamaba a la elaboración de postulados propios para explicar la génesis de la criminalidad. Este es el caso del concepto de criminicultura, con el que la policía definía la forma de vida característica de las clases bajas en tiempos en que la cuestión social dejaba al descubierto la miseria cotidiana del proletariado. Las migraciones, la cesantía o la explotación infantil eran vistas desde un marco explicativo que resaltaba la influencia del medio social en el comportamiento, lo que se matizaba con una mirada determinista, de forma que el tránsito hacia la conducta criminal estaba precedido por una ecuación precisa que combinaba vagancia y alcoholismo. El potencial criminal se encontraba en las calles y en los negocios que atentaban contra las malas costumbres, frente a lo cual emergía la misión policial regeneradora.

De esta forma, se establecía un propio marco de análisis para entender el origen del delito y con ello la acción preventiva a cargo de las policías. Este marco explicativo contenía un componente de eclecticismo en el que confluían postulados del determinismo, las miradas de las elites y su influencia en la prensa y la propia confianza policial depositada en el conocimiento práctico. Con ello, se ratificaban los discursos y practicas segregadoras del modo de vida de las clases bajas, elaborados en base a estereotipos y prejuicios sobre los portadores de una cultura diferenciada del "nosotros". El caso de Dubois, es quizás representativo de las consecuencias de este cautiverio teórico-práctico, que dejaba al descubierto las serias deficiencias de los cuerpos policiales urbanos para detener un tipo de delito que escapaba a su marco explicativo en los albores del siglo $\mathrm{XX}$.

RECEBIDO EM: 15/05/2016

APROVADO EM: 20/06/2016 